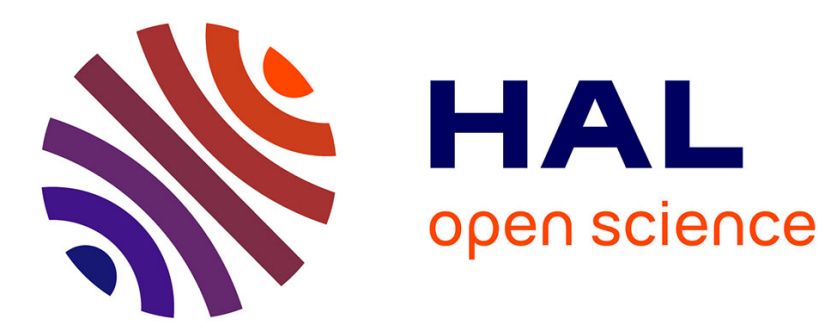

\title{
Single-template periodic mesoporous organosilica with organized bimodal mesoporosity
}

M. Wong Chi Man, M. Laird, C. Carcel, E. Oliviero, Guillaume Toquer, P. Trens, J.R. R Bartlett, M Wong, Chi Man

\section{- To cite this version:}

M. Wong Chi Man, M. Laird, C. Carcel, E. Oliviero, Guillaume Toquer, et al.. Single-template periodic mesoporous organosilica with organized bimodal mesoporosity. Microporous and Mesoporous Materials, 2020, 297, pp.110042. 10.1016/j.micromeso.2020.110042 . hal-03095103

\section{HAL Id: hal-03095103 https://hal.science/hal-03095103}

Submitted on 4 Jan 2021

HAL is a multi-disciplinary open access archive for the deposit and dissemination of scientific research documents, whether they are published or not. The documents may come from teaching and research institutions in France or abroad, or from public or private research centers.
L'archive ouverte pluridisciplinaire HAL, est destinée au dépôt et à la diffusion de documents scientifiques de niveau recherche, publiés ou non, émanant des établissements d'enseignement et de recherche français ou étrangers, des laboratoires publics ou privés. 


\title{
Single-template periodic mesoporous organosilica with organized bimodal mesoporosity
}

\author{
M. LAIRD ${ }^{\mathrm{a}}$, C. CARCEL $^{\mathrm{a}}$, E. OLIVIERO ${ }^{\mathrm{a}}$, G. TOQUER $^{\mathrm{b}}$, P. TRENS ${ }^{\mathrm{a}}, \mathrm{J}$. R. \\ BARTLETT $^{\mathrm{c}^{*}}$, M. WONG CHI MAN ${ }^{\mathrm{a}^{*}}$ \\ ${ }^{\text {a }}$ ICGM, University of Montpellier, CNRS, ENSCM, Montpellier, France \\ (email: michel.wong-chi-man@enscm.fr) \\ ${ }^{b}$ ICSM, University of Montpellier, CEA, CNRS, ENSCM, Marcoule, France \\ ${ }^{c}$ Western Sydney University, Locked Bag 1797, Penrith NSW 2751 Australia \\ (email: j.bartlett@westernsydney.edu.au)
}

\begin{abstract}
Periodic mesoporous organosilicas (PMOs) are obtained by the hydrolysiscondensation of organobridged triethoxysilane precursors in the presence of surfactants as structure-directing agents (SDAs). After removal of the SDAs, the resulting materials usually exhibit monomodal, well-organized mesoporosity, with the size of the pores being controlled by the SDA. However, despite the potential technological applications of such materials with well-organized bimodal porosity, to the best of our knowledge, PMOs exhibiting two distinct types of ordered mesoporosity have barely been described.

Herein, we describe a simple approach for modulating the dimensions of ordered monomodal 2D hexagonal and bimodal porosity in PMOs synthesized from 1,4-bis(triethoxysilyl)benzene (BTEB) and Pluronic P123 under acidic conditions, by varying the addition sequence of reactants. The approach employs a single SDA without degradation of the BTEB precursor. Reaction conditions leading to the formation of monomodal and bimodal porosity within the templated PMOs are identified. Our approach exploits the competition between the rates of (a) BTEB hydrolysis/condensation; and (b) diffusion, solubilization and partitioning of the unhydrolyzed and hydrolyzed precursor within the micelles. A mechanism describing the evolution of porosity within this system is proposed.
\end{abstract}




\section{Keywords}

Periodic Mesoporous Organosilica, Dual porosity, Bimodal porosity

\section{Introduction}

Highly porous materials based on silica have been prepared using a wide range of synthetic strategies and are now routinely exploited in many fields [1], including catalysis $[2,3]$, chromatography [4, 5], nuclear waste storage [6], insulation [7], optics [8], electronics [9], biocatalysis and biosensors [10-12]. The scope of such systems in applied materials science was profoundly impacted by the first reports of the successful preparation of periodic mesoporous silica (PMS) in the early 1990s [13], which exploited the use of surfactants as structure-directing agents (SDAs) to obtain pure mesoporous silica with well-organized and uniform pores. The framework structure and pore size/volume, together with the wall thickness, are modulated by careful selection of process parameters (including the nature of the SDA, use of swelling agents, temperature, solvent, etc), and the formation of several types of mesostructured silica, among which the cubic, 2D hexagonal and lamellar structures are most commonly obtained, has now been well-documented [14].

The utility of such organized mesoporous systems was further extended through the use of organosilane precursors (mono-silylated organics mixed with silica sources [15]) and by the first reports of the preparation of periodic mesoporous organosilica (PMO) analogues of PMS in 1999 [16-18]. A significant body of work has now emerged around control of the structure and properties of these latter materials for applications in such 
diverse areas as optics, catalysis, nanomedicine, separation science, etc [19-30]. PMOs with high surface areas and uniform porosity are typically obtained via the hydrolysispolycondensation of organosilanes with general stoichiometry $\left(\mathrm{R}^{\prime} \mathrm{O}\right)_{3} \mathrm{Si}-\mathrm{R}-\mathrm{Si}(\mathrm{OR})_{3}$ using appropriate SDAs. The organic functions (R) in the precursor are covalently bridged between two $\mathrm{Si}$ atoms, which ensures their regular distribution within the pore walls of the PMOs [31], while the range of potential bridging groups enables a correspondingly wide variety of functionalities to be introduced into the mesoporous hybrids $[24,32,33]$.

A variety of SDAs have now been reported for the preparation of PMOs, which enable the pore size to be readily tuned from around $2 \mathrm{~nm}$ to more than $10 \mathrm{~nm}$ [34]. The SDAs employed include simple surfactants such as cetyltrimethylammonium bromide $\left.\left(\left(\mathrm{C}_{16} \mathrm{H}_{33}\right) \mathrm{N}\left(\mathrm{CH}_{3}\right)_{3} \mathrm{Br}\right), \quad \mathrm{CTAB}\right), \quad$ Gemini molecules $\left(\mathrm{C}_{\mathrm{n}} \mathrm{H}_{2 \mathrm{n}+1} \mathrm{~N}\left(\mathrm{CH}_{3}\right)_{2}\left(\mathrm{CH}_{2}\right)_{\mathrm{s}} \mathrm{N}\left(\mathrm{CH}_{3}\right)_{2} \mathrm{C}_{\mathrm{n}} \mathrm{H}_{2 \mathrm{n}+1}\right)$ [35], triblock copolymers such as Pluronic P123 ((EO) $)_{20}(\mathrm{PO})_{70}(\mathrm{EO})_{20}[36]$ and polyion complex micelle species [29]. More sophisticated strategies involving the use of surfactant mixtures, co-solvents and cosurfactants as pore expanders [37], together with judicious control of $\mathrm{pH}$, ionic strength and other key sol-gel process parameters [38-40] have also been reported. Well-organized porosity with controlled symmetry (e.g. 2D hexagonal, 3D hexagonal, cubic, etc), together with uniform pore sizes, can be readily obtained in such systems, with the range of applications critically dependent on both the functionality of the bridging species and the control of pore size and symmetry. A model describing the synergistic interactions between the SDA and precursor molecules during the evolution of templated porous structures has been proposed by Polarz and Antonietti [41]. In this so-called three-phase model, the hydrophobic domain of the surfactant and a depleted corona region at the 
interface between the hydrophobic and hydrophilic regions control the size of the templated mesoporosity, while the hydrophilic chains typically interact with the evolving silicate or silsesquioxane framework and can contribute to the development of microporosity in the materials. The intrinsic hydrophobicity of the organic PMO precursors favors their solubility within the hydrophobic core and/or interface regions of the micelle, often leading to smaller pore sizes than would typically be observed for purely silica-based analogues [19].

A potential limitation of current approaches for producing such materials is that the pore size distributions obtained are typically monomodal, with few reports of synthesis strategies leading to bimodal porosity in PMOs having appeared [42-44] (in contrast to PMS-based systems [45-48]). However, many potential applications for such materials can be envisaged that would be greatly enhanced by the presence of well-organized bimodal porosity, including catalysis (control of the diffusion rates of reactants and products of different dimensions); chromatography (enhanced double-size exclusion); and controlled delivery of bioactive species (tailored release profiles of mixtures of pharmaceuticals); etc. Interestingly, bimodal porosity has also been obtained with the use of two different organosilanes. Indeed, such materials have been reported when (1,4-bis(triethoxysilyl)benzene (BTEB) and vinyltriethoxysilane are simultaneously added to the SDA solution [43]. A proposed mechanism suggests that the bimodality results from the vinyltriethoxysilane interaction with the corona of the SDA micelle, which increases the pore size. A similar result is obtained upon stepwise hydrolysis of two bridged organosilanes (1,2-bis(triethoxysilyl)ethene (BTSEENE) and BTEB), where mesoporous multipods were synthesized. It was demonstrated that the BTSEENE mesoporous nanorods grow onto the mesoporous spherical BTEB [49]. These complex 
systems require the use of several organosilane precursors. When using only BTEB with P123 as surfactant, either 2D-hexagonal or cubic mesostructured PMOs are generally obtained [36, 42].

In this paper, we describe a simple approach for modulating the dimensions of ordered porosity in PMOs synthesized from BTEB and the symmetric triblock copolymer Pluronic P123 under acidic conditions, by varying the addition sequence of reactants. Reaction conditions leading to the formation of monomodal and bimodal porosity within the templated PMOs are identified. Our approach exploits the competition between the rates of (a) BTEB hydrolysis/condensation; and (b) diffusion, solubilization and partitioning of the unhydrolyzed and hydrolyzed BTEB sol-gel precursor within the threephase regions of the self-assembling P123 SDA. A mechanism describing the evolution of porosity within this system is proposed.

\section{Experimental}

\subsection{Chemicals}

1,4-Bis(triethoxysilyl)benzene (BTEB) was synthesized using the previously described method $[50,51]$ and purified by distillation under vacuum. Pluronic P123 was obtained from Sigma Aldrich. Hydrochloric acid 35\% (Rectapur), water (HPLC grade), ethanol (absolute grade) and acetone (Normapur) were obtained from VWR and used as received.

\subsection{PMO synthesis}

All syntheses were based on Inagaki's approach [36] and extracted according to Wang's method [52]. 
PMO-1: In a Schlenk vessel, Pluronic P123 (1.46 g, $218 \mu \mathrm{mol})$ was dissolved at $35{ }^{\circ} \mathrm{C}$ in water $(53.5 \mathrm{~mL})$ under strong agitation (1400 rpm). Concentrated $\mathrm{HCl}(310 \mu \mathrm{L}$, $3.5 \mathrm{mmol} \mathrm{HCl}$ ) was added to the previous solution and the resulting mixture was then cooled to $0{ }^{\circ} \mathrm{C}$. The BTEB $(1.5 \mathrm{~g}, 3.7 \mathrm{mmol})$ was added dropwise to the cold solution. After $1 \mathrm{~h}$ of reaction, the reacting mixture was heated to $35^{\circ} \mathrm{C}$ for $24 \mathrm{~h}$ and then to 100 ${ }^{\circ} \mathrm{C}$ for an additional $24 \mathrm{~h}$. The white solid obtained was recovered by centrifugation, washed with water until the $\mathrm{pH}$ of the supernatant reached 6.5 and then returned to the vessel in $53.5 \mathrm{~mL}$ of water at $100{ }^{\circ} \mathrm{C}$ for further aging and structural consolidation for three days. The resulting solid was then recovered by centrifugation, washed once with water, three times with acetone and dried under vacuum to afford $804 \mathrm{mg}$ of white powder. The resulting material $(550 \mathrm{mg}$ ) was extracted in an acidic solution of ethanol (4.3 $\mathrm{mL}$ of concentrated $\mathrm{HCl}$ in $143 \mathrm{~mL}$ of ethanol). The hybrid silica was finally recovered by centrifugation, washed with water until the $\mathrm{pH}$ of the supernatant reached 6.5 , then washed with acetone (three times) and dried under vacuum to obtain $485 \mathrm{mg}$ of white powder. ${ }^{13} \mathrm{C}$ NMR (75 MHz, CP-MAS, ppm): 132.7 (aromatics), $58.6\left(\mathrm{CH}_{3}-\mathbf{C H}_{2}\right.$ O), $17.0\left(\mathbf{C H}_{3}-\mathrm{CH}_{2}-\mathrm{O}\right) .{ }^{29} \mathrm{Si} \mathrm{NMR}(60 \mathrm{MHz}, \mathrm{CP}-\mathrm{MAS}, \mathrm{ppm}):-62.0\left(\mathrm{~T}^{1}\right),-71.0\left(\mathrm{~T}^{2}\right),-79.4$ $\left(\mathrm{T}^{3}\right)$. IR $\left(\mathrm{cm}^{-1}\right): 1036(v(\mathrm{Si}-\mathrm{O}-\mathrm{Si})), 914\left(\delta\left(\mathrm{C}_{\mathrm{sp} 2}-\mathrm{H}\right)\right)$.

PMO-2: In a first Schlenk vessel, Pluronic P123 (1.46 g, $218 \mu \mathrm{mol})$ was dissolved at $35{ }^{\circ} \mathrm{C}$ in water $(53.5 \mathrm{~mL})$ under strong agitation $(1400 \mathrm{rpm})$. Concentrated $\mathrm{HCl}$ $(310 \mu \mathrm{L}, 3.5 \mathrm{mmol} \mathrm{HCl})$ was added to the previous solution and the resulting mixture was then cooled to $0{ }^{\circ} \mathrm{C}$. In a second flame dried Schlenk flask, BTEB (1.5 g, $\left.3.73 \mathrm{mmol}\right)$ was added and cooled to $0{ }^{\circ} \mathrm{C}$ under magnetic stirring (750 rpm agitation). $20 \mathrm{~mL}$ of the 
surfactant solution was then poured into the flask containing BTEB and the agitation speed was immediately increased up to $1400 \mathrm{rpm} .5 \mathrm{~min}$ later, the remaining surfactant solution was quickly added. After $1 \mathrm{~h}$ of reaction, the reacting mixture was heated up to $35^{\circ} \mathrm{C}$ for $24 \mathrm{~h}$ and then to $100{ }^{\circ} \mathrm{C}$ for an additional $24 \mathrm{~h}$. The white solid obtained was recovered by centrifugation, washed with water until the $\mathrm{pH}$ of the supernatant reached 6.5 and then returned to the vessel in $53.5 \mathrm{~mL}$ of water at $100{ }^{\circ} \mathrm{C}$ for further ageing and structural consolidation for three days. The resulting solid was then recovered by centrifugation, washed once with water, three times with acetone and dried under vacuum to afford $839 \mathrm{mg}$ of white powder. The resulting material $(550 \mathrm{mg})$ was extracted in an acidic solution of ethanol ( $4.3 \mathrm{~mL}$ of concentrated $\mathrm{HCl}$ in $143 \mathrm{~mL}$ of ethanol). The hybrid silica was finally recovered by centrifugation, washed with water until the $\mathrm{pH}$ of the supernatant reached 6.5, then washed with acetone (three times) and dried under vacuum to obtain $443 \mathrm{mg}$ of white powder. ${ }^{13} \mathrm{C}$ NMR (75 MHz, CP-MAS, ppm): 132.6 (aromatics), $58.3\left(\mathrm{CH}_{3}-\mathbf{C H}_{2}-\mathrm{O}\right), 16.4\left(\mathbf{C H}_{3}-\mathrm{CH}_{2}-\mathrm{O}\right) .{ }^{29} \mathrm{Si}$ NMR (60 MHz, CP-MAS, ppm): -62.0 ( $\left.\mathrm{T}^{1}\right),-71.2\left(\mathrm{~T}^{2}\right),-78.6\left(\mathrm{~T}^{3}\right) . \quad \mathrm{IR}\left(\mathrm{cm}^{-1}\right): 1036(v(\mathrm{Si}-\mathrm{O}-\mathrm{Si})), 914\left(\delta\left(\mathrm{C}_{\mathrm{sp} 2}-\mathrm{H}\right)\right)$

PMO-3: In a first Schlenk vessel, Pluronic P123 (1.46 g, $218 \mu \mathrm{mol})$ was dissolved at $35^{\circ} \mathrm{C}$ in water $(53.5 \mathrm{~mL})$ under strong agitation $(1400 \mathrm{rpm})$. Concentrated $\mathrm{HCl}(310$ $\mu \mathrm{L}, 3.5 \mathrm{mmol} \mathrm{HCl}$ ) was added to the previous solution and the resulting mixture was then cooled to $0{ }^{\circ} \mathrm{C}$. In a second flame dried Schlenk flask, BTEB (1.5 g, $\left.3.73 \mathrm{mmol}\right)$ was added and cooled to $0{ }^{\circ} \mathrm{C}$ under magnetic stirring (750 rpm agitation). $18 \mathrm{~mL}$ of the surfactant solution was then poured into the flask containing BTEB and the agitation speed was immediately increased up to $1400 \mathrm{rpm}$. After $1 \mathrm{~h}$, the temperature of the reaction mixture was increased to $35^{\circ} \mathrm{C}$ for $24 \mathrm{~h}$, and then to $100{ }^{\circ} \mathrm{C}$ for an additional 
$24 \mathrm{~h}$. The white solid obtained was recovered by centrifugation, washed with water until the $\mathrm{pH}$ of the supernatant reached 6.5 and then returned to the vessel in $53.5 \mathrm{~mL}$ of water at $100{ }^{\circ} \mathrm{C}$ for further ageing and structural consolidation for three days. The resulting solid was then recovered by centrifugation, washed once with water, three times in acetone and dried under vacuum to afford $764 \mathrm{mg}$ of white powder. The resulting material $(550 \mathrm{mg})$ was extracted in an acidic solution of ethanol $(4.3 \mathrm{~mL}$ of concentrated $\mathrm{HCl}$ in $143 \mathrm{~mL}$ of ethanol). The hybrid silica was finally recovered by centrifugation, washed with water until the $\mathrm{pH}$ of the supernatant reached 6.5 , then washed with acetone (three times) and dried under vacuum to obtain $451 \mathrm{mg}$ of white powder. ${ }^{13} \mathrm{C}$ NMR $(75 \mathrm{MHz}, \mathrm{CP}-\mathrm{MAS}$, ppm): 132.7 (aromatics), $58.3\left(\mathrm{CH}_{3}-\mathbf{C H}_{2}-\mathrm{O}\right), 16.2\left(\mathbf{C H}_{3}-\mathrm{CH}_{2}-\mathrm{O}\right) .{ }^{29} \mathrm{Si} \mathrm{NMR}(60 \mathrm{MHz}$, CP-MAS, ppm): -62.7 $\left(\mathrm{T}^{1}\right),-71.5\left(\mathrm{~T}^{2}\right),-79.5\left(\mathrm{~T}^{3}\right) . \quad$ IR $\left(\mathrm{cm}^{-1}\right): 1039(v(\mathrm{Si}-\mathrm{O}-\mathrm{Si})), 914$ $\left(\delta\left(\mathrm{C}_{\mathrm{sp} 2}-\mathrm{H}\right)\right)$

\subsection{Characterization}

${ }^{29} \mathrm{Si}$ and ${ }^{13} \mathrm{C}$ solid-state NMR spectra were obtained using cross-polarization and magic-angle spinning techniques (CP-MAS) on a Varian VNMR $300 \mathrm{MHz}$ spectrometer. Thermogravimetric analyses (TGA) were performed on a TA Instruments Q50 apparatus with a heating rate of $10{ }^{\circ} \mathrm{C} \cdot \mathrm{min}^{-1}$ under an air flow of $60 \mathrm{~mL} \cdot \mathrm{min}^{-1}$. The material decomposition was studied from $25^{\circ} \mathrm{C}$ up to $800{ }^{\circ} \mathrm{C}$. Transmission electron microscopy (TEM) images were obtained on a JEOL $1400 \mathrm{P}+$ microscope operating at $120 \mathrm{kV}$ with a $\mathrm{LaB}_{6}$ source. Samples were prepared by microtome with a nominal thickness of around $70 \mathrm{~nm}$. Fast-Fourier transform (FFT) analyses of selected regions of the TEM images were obtained using ImageJ software (Version 1.52a). Scanning Electron Microscopy (SEM) measurements were carried out using a Hitachi S4800 apparatus on platinum 
metalized samples. Nitrogen physisorption isotherms were determined at $77.35 \mathrm{~K}$ using a Micromeritics ASAP 2020 machine. The activation of the materials was performed at $100{ }^{\circ} \mathrm{C}$ for $12 \mathrm{~h}$ under secondary vacuum. The specific surface area of the materials was determined using the BET model in the relative pressure range $0.05<\mathrm{p} / \mathrm{p}^{\circ}<0.25$, taking $0.162 \mathrm{~nm}^{2}$ as the cross-sectional area for adsorbed nitrogen molecules. The $\alpha_{\mathrm{s}}$ model was used for evaluating the presence of micropores and deriving the corresponding micropores volume, using Aerosil200 as reference.

The small- and wide-angle X-ray scattering (SWAXS) experiments were performed using a Guinier-Mering set-up coupled with a 2D image plate detector. The X-ray source was a molybdenum anode, delivering a high energy monochromatic beam $(\lambda=0.71 \AA, \mathrm{E}$ $=17.4 \mathrm{keV}$ ) and providing structural information over scattering vectors $q$ ranging from 0.02 to $2.5 \AA^{-1}$. The region between the sample and the image plate was purged with flowing helium, to avoid air absorption. The data acquisition time was $3600 \mathrm{~s}$ and the glass capillaries used to hold the samples (Higenberg) had a thickness of $2 \mathrm{~mm}$. The image azimuthal average was determined using FIT2D software from ESRF (France), and data corrections and radial averaging were performed via standard procedures.

\section{Results and discussion}

\subsection{Structure and morphology of PMOs}

The ${ }^{13} \mathrm{C}$ NMR spectra of all materials show similar profiles (Fig. S1, Supporting Information) and reflect the presence of the phenylene bridging group as well as small quantities of residual ethoxy groups. In the ${ }^{29} \mathrm{Si}$ NMR spectra, three signals corresponding to $\mathrm{T}^{1}, \mathrm{~T}^{2}$ and $\mathrm{T}^{3}$ silsesquioxane moieties are observed in all cases with comparable relative intensities (Fig. S2, Supporting Information). The predominance of $\mathrm{T}^{2}$ species indicates 
that condensation is not complete and reflects the relatively slow kinetics of condensation under the acidic conditions used to synthesize the samples. Furthermore, no signals are visible below $-100 \mathrm{ppm}$ which indicates that no $\mathrm{Si}-\mathrm{C}$ bond cleavage occurred. The ${ }^{29} \mathrm{Si}$ NMR spectrum of PMO-2 is presented in Fig. 1.

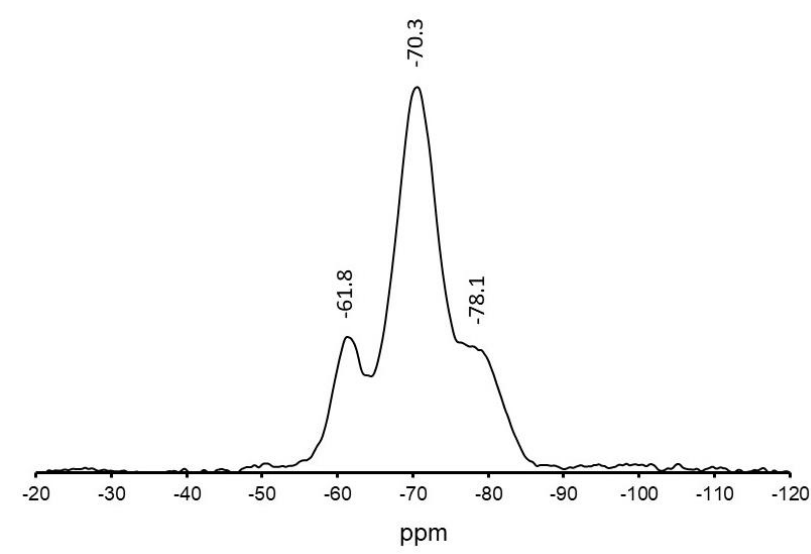

Fig. $1 .{ }^{29} \mathrm{Si}$ CP-MAS NMR spectrum of PMO-2

The FTIR spectra of PMO-1, PMO-2 and PMO-3 (Fig. S3, Supporting Information) exhibit the typical features expected for such hybrid materials [49]. Additional weak aliphatic $v(\mathrm{c}-\mathrm{H})$ modes are also evident from 2800 to $3000 \mathrm{~cm}^{-1}$, which are attributed to the residual ethoxy species already identified by ${ }^{13} \mathrm{C}$ NMR (Fig. S1, Supporting Information).

Thermogravimetric analyses of the samples are illustrated in Fig. 2. 


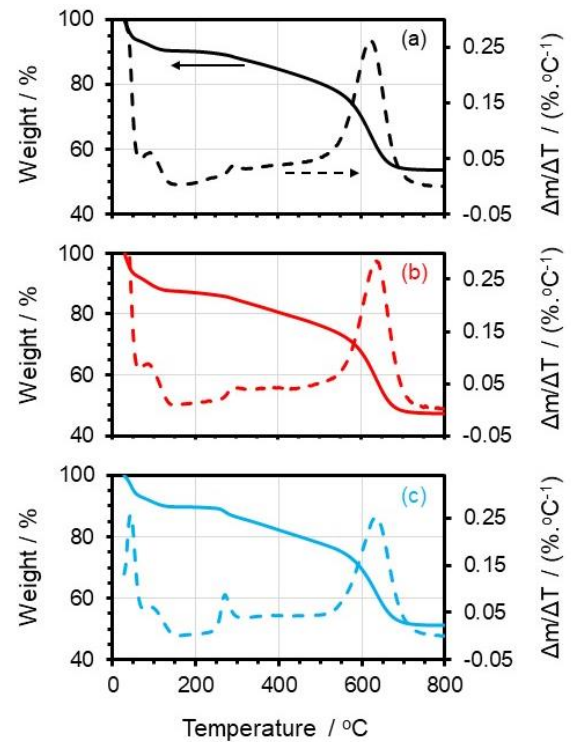

Fig. 2. Thermogravimetric analysis of PMO-1 (a); PMO-2 (b); and PMO-3 (c)

All samples exhibit similar features, which are consistent with their expected similar compositions. The plateau observed in the TGA data between 150 and $200{ }^{\circ} \mathrm{C}$ and weight loss $(\Delta \mathrm{m})$ at temperatures below $150{ }^{\circ} \mathrm{C}$ are consistent with the initial removal of water (between 6.7 and $7.5 \%$ ), which occurs in two stages (based on the corresponding dTGA data). Below $75^{\circ} \mathrm{C}$, the water removal can be attributed to loss of residual "bulk" water retained within the pores after acid treatment, which is only weakly bound to the materials. Between 75 and $150{ }^{\circ} \mathrm{C}$, a second stage is observed, which is attributed to the loss of water molecules more strongly bound to the structures. The subsequent degradation of the materials occurs above $250{ }^{\circ} \mathrm{C}$, commencing with a small $\Delta \mathrm{m}$ at around $280{ }^{\circ} \mathrm{C}$, a continuous and moderate $\Delta \mathrm{m}$ up to $600{ }^{\circ} \mathrm{C}$ and a significant $\Delta \mathrm{m}$ between $600{ }^{\circ} \mathrm{C}$ and $700{ }^{\circ} \mathrm{C}$. The $\Delta \mathrm{m}$ at $280{ }^{\circ} \mathrm{C}(2 \%)$ is tentatively attributed to the removal of residual organic species that were not released from the pores after acidic treatment. The continuous $\Delta \mathrm{m}$ (around $12 \%$ ) could correspond to the loss of geminal or isolated silanols [53]. In the same temperature range, it can be assumed that the degradation of the structure is also initiated through the oxidation of phenyl groups grafted onto the inorganic 
framework, as previously reported for the degradation of hydrocarbons such as polymers or surfactants $[54,55]$. Above $600{ }^{\circ} \mathrm{C}$, the degraded organic species decompose. The residual quantities of $\mathrm{SiO}_{2}$ above $700{ }^{\circ} \mathrm{C}$ are very similar, which indicates that the structuration of the three materials involves similar inorganic/organic molar ratios. This is consistent with the proportions of reagents used for the synthesis of the three materials.

The nitrogen sorption isotherms of the three materials are presented in Fig. 3.
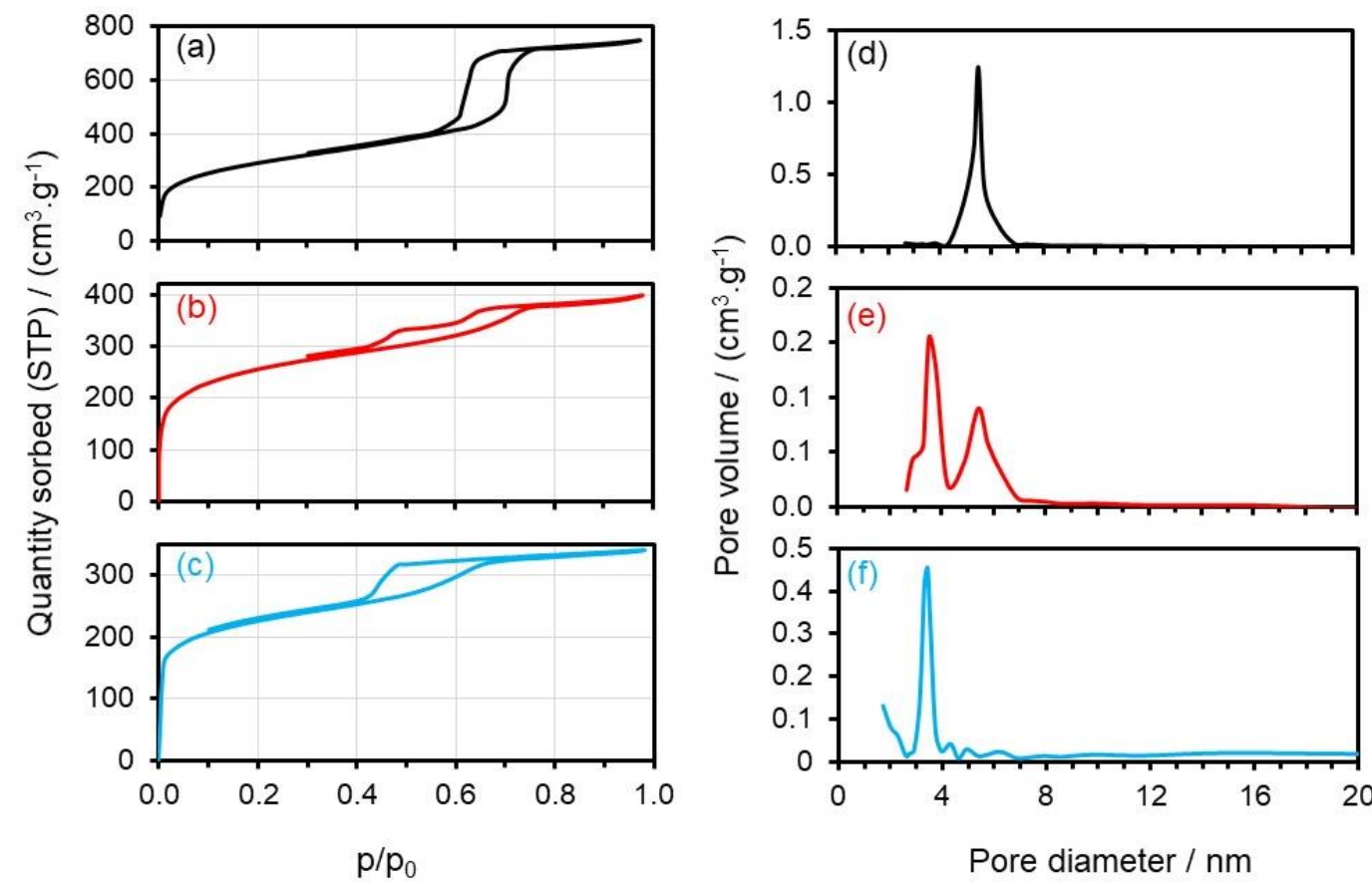

Fig. 3: Nitrogen physisorption isotherms of PMO-1 (a); PMO-2 (b); PMO-3 (c); and the corresponding BJH plots of PMO-1 (d); PMO-2 (e); and PMO-3 (f)

The curves obtained are typical type IV sorption isotherms, characterized by a strong uptake at intermediate relative pressure, followed by very flat plateaus. Additionally, the $\alpha_{\text {s }}$ plots, determined taking Aerosil 200 as a reference, revealed the absence of significant microporosity for these materials. Despite these common features, striking differences are evident. In the case of PMO-1 (Fig. 3(a)), the hysteresis loop is characterized by two parallel branches, which is consistent with materials exhibiting wellorganized mesoporosity. Interestingly, the high steepness of the uptake is an indication 
that the mesoporosity is extremely homogeneous. This is confirmed by the $\mathrm{BJH}$ pore size distribution determined using the desorption branch of the sorption isotherm, starting from $\mathrm{p} / \mathrm{p}^{\circ}=0.95$ for the derivation of the pore size distribution (Fig. 3(d)), where a very narrow peak centered at around $5.8 \mathrm{~nm}$ can be seen. In terms of pore volume, the capillary condensation process corresponds to about $50 \%$ of the overall pore volume, which indicates that this material is essentially mesoporous, with very limited amorphous domains. This is confirmed by the high specific area obtained for this material, $1040 \mathrm{~m}^{2} \cdot \mathrm{g}^{-1}$ (Table 1).

Table 1. Textural properties of PMO-1, PMO-2 and PMO-3

\begin{tabular}{|c|c|c|c|c|}
\hline & \multirow[t]{2}{*}{ PMO-1 } & \multicolumn{2}{|c|}{ PMO-2 } & \multirow[t]{2}{*}{ PMO-3 } \\
\hline & & $1^{\text {st }}$ population & $2^{\text {nd }}$ population & \\
\hline $\begin{array}{l}\text { BET specific } \\
\text { surface area } \\
\left(\mathrm{m}^{2} / \mathrm{g}\right)\end{array}$ & 1040 & \multicolumn{2}{|c|}{952} & 723 \\
\hline $\begin{array}{l}\text { BJH pore size } \\
(\mathrm{nm})\end{array}$ & 5.8 & 5.8 & 3.9 & 3.9 \\
\hline $\begin{array}{c}\text { SWAXS } \\
\text { periodicity }(\mathrm{nm})\end{array}$ & 11.3 & 11.5 & 16.1 & 11.5 \\
\hline $\begin{array}{l}\text { Wall thickness } \\
\qquad(\mathrm{nm})\end{array}$ & 5.5 & 5.7 & $\geq 12$ & $7.6-9.1$ \\
\hline $\begin{array}{l}\text { Pore volume } \\
\left(\text { des., } \mathrm{cm}^{3} / \mathrm{g} \text { ) }\right.\end{array}$ & 1.04 & & & 0.38 \\
\hline
\end{tabular}

In the case of PMO-2 (Fig. 3(b)), whereas the saturation plateau is still present, the uptake at intermediate relative pressure is less pronounced. Indeed, the saturation plateau is located at around $380 \mathrm{~cm}^{3} \cdot \mathrm{g}^{-1}$ which is one half of the saturation plateau obtained for PMO-1. It can be deduced that this material is not as mesoporous as the material prepared using the pathway of PMO-1. On the other hand, the specific surface area is $952 \mathrm{~m}^{2} \cdot \mathrm{g}^{-1}$, quite close to that obtained for PMO-1. This is consistent with the fact that the sorption isotherms for both samples are very similar at low relative pressure as shown in Fig. 4. 


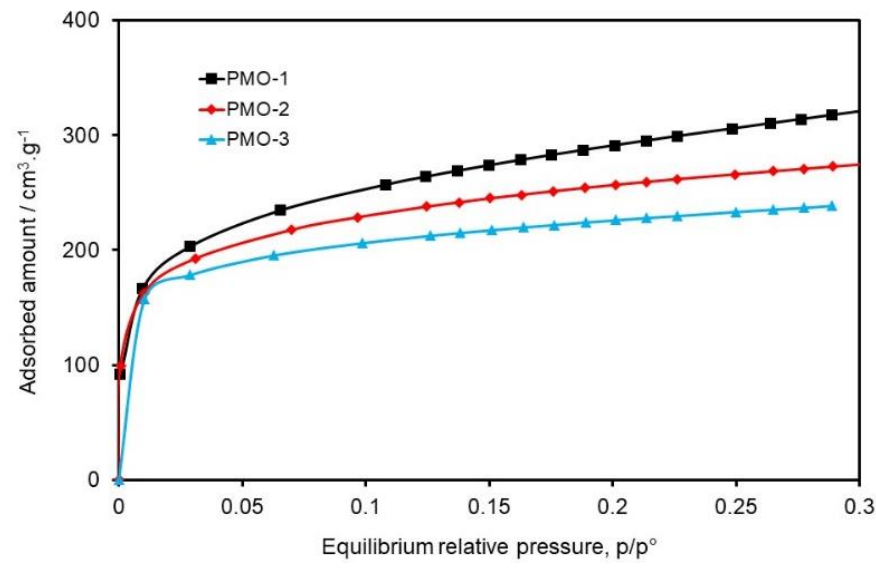

Fig. 4: Nitrogen adsorption isotherms at low relative pressure for PMO-1, PMO-2 and PMO-3.

It can be deduced that PMO-1 has a larger population of mesopores, favoring larger amounts of condensed sorbate. In other words, the pore walls are likely thicker in the case of PMO-2 (see discussion below and Table 1). Additionally, the uptake at intermediate relative pressure is not very steep, which is an indication that the material has mesopores of different sizes. More importantly, the shapes of the hysteresis loops are very different. In the case of PMO-2, the hysteresis branches are no longer parallel, and two desorption regimes can be distinguished. The shape of the hysteresis loop can be interpreted by determining the pore size distribution using the $\mathrm{BJH}$ method, obtained using the desorption branch. In Fig. 3(e), two peaks can be seen, which are attributed to two populations of mesopores with average diameters of 3.9 and $5.8 \mathrm{~nm}$. It is noted that in this material, the latter pore diameter is identical to that found in PMO-1. Therefore, the data indicate that PMO-2 exhibits bimodal mesoporosity, whereas PMO-1 exhibits uniform, monomodal mesopores [36].

In the case of PMO-3 (Fig. 3(c)), the saturation plateau is very close to that found with PMO-2 (at around $350 \mathrm{~cm}^{3} \cdot \mathrm{g}^{-1}$ ). However, a significant difference can be seen in the shape of the hysteresis loop. The branches are not parallel and there is only one 
desorption step, as found with PMO-1. It can be deduced that PMO-3 has only one population of mesopores, as confirmed by Fig. 3(f) where the BJH plot of the material is illustrated. Interestingly, the mean pore diameter is centered at $3.9 \mathrm{~nm}$, which corresponds to one of the two pore sizes found for PMO-2. From the sorption analysis, it can be deduced that if PMO-1 and PMO-3 are mesoporous materials, with uniform, monomodal pore diameters related to the structuration of the materials, then PMO-2 has two different populations of uniform mesopores. More importantly, these two populations of mesopores are found together in PMO-2, which exhibits a bimodal pore size distribution. This interpretation is consistent with the specific surface area obtained with PMO-3, $723 \mathrm{~m}^{2} \cdot \mathrm{g}^{-1}$. Indeed, if PMO-2 has a bimodal mesoporosity, its surface area should lie between those found for PMO-1 and PMO-3, which is precisely the case.

The differences in the adsorption and desorption isotherm branches in the case of PMO-2 (with the latter showing two distinct steps, in contrast to the single step seen for the former) can be attributed to percolation (bottle-neck) effects in such porous networks, as described by Rouquerol et al [56]. As two populations of mesopores are present in this material, the large pores will be emptied first, at a relative pressure which corresponds, through Kelvin's law, to the size of the smaller mesopores. Hence, a large decrease in the quantity of adsorbed gas can be seen in the first desorption stage. The smaller mesopores, in turn, will be emptied at lower relative pressure. In particular, the voids are emptied at relative pressures that satisfy the Kelvin law for void opening sizes, and hence, two steps are observed during desorption. This does not occur during the filling process, and hence only a single step is observed during adsorption. In addition, attempts to simulate the isotherms for PMO-2 by using simple linear combinations of the isotherms for PMO-1 and PMO-3 did not identify any combinations that led to a good fit to the isotherms for 
PMO-2. These data indicate that PMO-2 is a unique material, and not a simple mixture of PMO-1 and PMO-3.

The relatively thick pore walls observed in the case of PMO-2 are also unusual, insofar as an increase in the thickness of the pore walls in such materials (Table 1) would normally be expected to result in a corresponding decrease in specific surface area and pore volume. However, in the present study, a comparison of the properties of PMO-1 and PMO-2 indicates that although the materials exhibit comparable surface areas, the wall thickness of PMO-1 is much lower than that of PMO-2. This further highlights the fact that PMO-2 with its bimodal porosity is a unique material, and a more complex system than PMO-1 and PMO-3. The smaller mesopores contribute to the total specific surface area to a greater extent than they do to the total pore volume. In PMO-2, these effects interact to ensure that the increasing wall thickness and the presence of two populations of mesopores leads to a decrease in total pore volume without a corresponding significant decrease in overall surface area.

The SAXS spectrum of PMO-1, shown in Fig. 5 (bottom), exhibits four well defined pseudo-Bragg peaks in the low $q$ region, at $6.4 \times 10^{-2}, 11.2 \times 10^{-2}, 12.9 \times 10^{-2}$ and $19.6 \times 10^{-2} \AA^{-1}$. This corresponds to $q_{0}, \sqrt{ } 3 q_{0}, \sqrt{ } 4 q_{0}, \sqrt{ } 9 q_{0}$, respectively, from a 2D hexagonal mesostructure (p6mm symmetry) with a lattice parameter $\mathrm{a}=11.3 \mathrm{~nm}\left(\mathrm{a}=4 \pi / \sqrt{ } 3 / \mathrm{q}_{0}\right)$. 


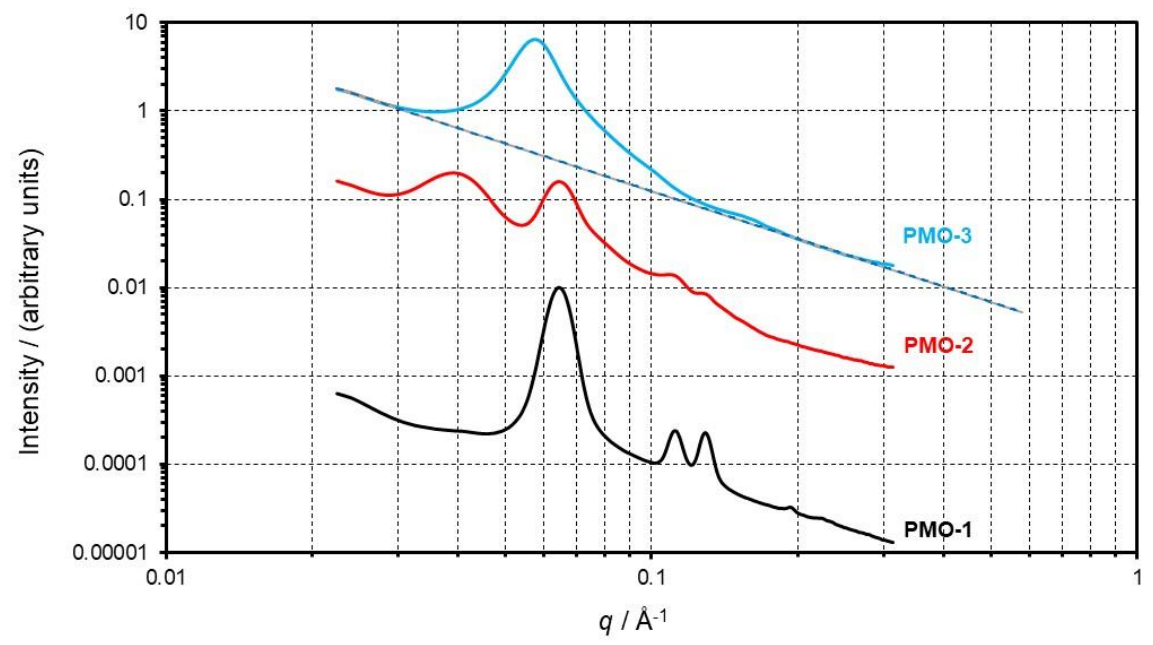

Fig. 5. SWAXS patterns for PMO-1 (bottom), PMO-2 (middle) and PMO-3 (top)

The TEM image confirms the 2D hexagonal phase (Fig. 6(a), see below), with a measured lattice parameter of $11.5 \pm 0.1 \mathrm{~nm}$ which is also in agreement with the SAXS data. The apparent wall thickness, calculated from the lattice parameter $a$ and the pore diameter determined via nitrogen adsorption $(5.8 \pm 0.5 \mathrm{~nm})$, is $5.5 \pm 0.6 \mathrm{~nm}$.

The SAXS spectrum of PMO-3 (Fig. 5, top) displays a relatively strong, broad peak at $5.7 \times 10^{-2} \AA^{-1}\left(q_{0}\right.$, corresponding to a characteristic distance of $\left.11 \mathrm{~nm}\right)$, together with a weaker peak at around $0.17 \AA^{-1}\left(3 \mathrm{q}_{0}\right)$. The shape of the scattering profile suggests the presence of an additional broad peak (or peaks) at around $0.1 \AA^{-1}$. On the basis of these data alone, it is not possible to unambiguously identify the symmetry of the uniform pore network in PMO-3, since the results are consistent with either hexagonal or cubic symmetry. However, FFT analysis of the TEM data from PMO-3 (Fig. 6, see below) suggests that the symmetry is hexagonal, with a corresponding lattice parameter $a=12.7$ $\mathrm{nm}\left(\mathrm{a}=4 \pi / \sqrt{3} / \mathrm{q}_{0}\right)$. Hence, the apparent wall thickness, based on the pore diameter deduced from the $\mathrm{BJH}$ analysis $(3.9 \mathrm{~nm}$ ), is $\sim 8.8 \mathrm{~nm}$ (assuming hexagonal symmetry), which is significantly thicker than for PMO-1. 
In contrast, the SAXS spectrum of PMO-2 (Fig. 5, middle) is more complex. Three peaks at $6.4 \times 10^{-2}, 11 \times 10^{-2}$ and $13 \times 10^{-2} \AA^{-1}$ are assigned to Bragg reflections from the (100), (110) and (200) planes under P6mm symmetry, clearly demonstrating the 2D hexagonal structure with the same lattice parameter as PMO-1 $(11.3 \mathrm{~nm})$. This is further confirmed by TEM measurement (see below), from which a lattice parameter of $11.5 \pm 0.5 \mathrm{~nm}$ is obtained (Fig. 6(c)). However, an additional low- $q$ signal observed at $3.9 \times 10^{-2} \AA^{-1}$ ( $q_{0}$, corresponding to a characteristic distance of $16 \mathrm{~nm}$ ) suggests the presence of a second uniform pore network, as also observed via TEM (see below). This bimodal material has a first wall thickness, calculated from the lattice parameter of the P6mm space group and the pore diameter determined via nitrogen adsorption $(5.8 \pm 0.5 \mathrm{~nm})$, at $5.5 \pm 0.5 \mathrm{~nm}$ associated with the $2 \mathrm{D}$ hexagonal phase, together with a larger wall thickness (pore diameter=3.9 nm) exceeding $12 \mathrm{~nm}$ associated with the second phase. In this system, SWAXS, nitrogen physisorption and TEM measurements (see below) are all consistent with the presence of two uniform mesoporous domains.

It should also be noted that in the WAXS region (high $q$ values), characteristic distances at $\mathrm{d}=7.6 \AA$ and $3.8 \AA$ ( $q$ value of 0.8 and $1.7 \AA^{-1}$, respectively) are observed for all samples (exemplified by the data for PMO-1 in Fig. S4), consistent with a crystallinelike framework with a molecular-scale periodicity. The first peak corresponds to the lamellar repetition of the aryl moieties in organosilane fragments, whereas the second is assigned to the distance between the phenylene bridges, which are ordered via $\pi-\pi$ interactions $[22,57]$.

TEM images obtained from the PMOs are illustrated in Fig. 6 and Fig. S5, together with FFT data obtained from selected regions of the images. The micrograph of PMO-1 
and corresponding FFT (Fig. 6(a)) exhibit monomodal, organized porosity with hexagonal symmetry, consistent with the SWAXS and $\mathrm{N}_{2}$ sorption data presented above.

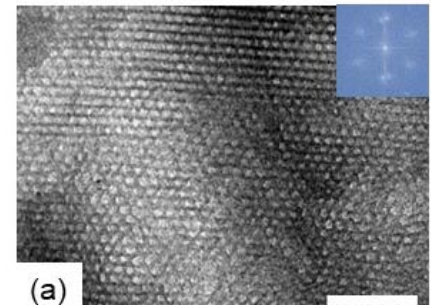

(a)

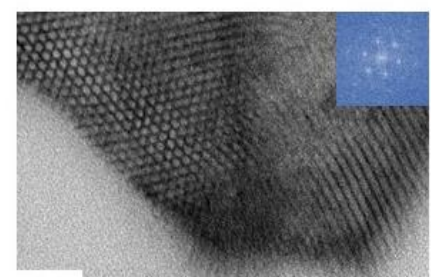

(c)

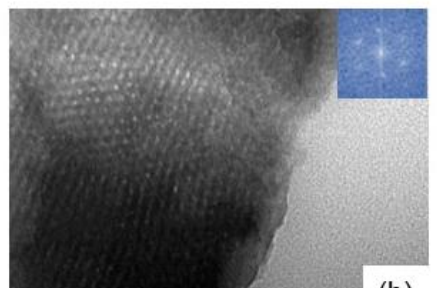

(b)

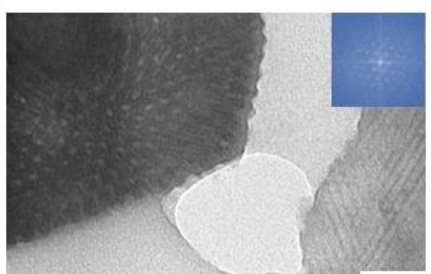

(d)

Fig. 6. TEM micrographs of PMO-1 (a); PMO-3 (b) and PMO-2 (c,d). (Size bar: 100 $\mathrm{nm})$. Inset: Fourier transforms of selected regions, highlighting pore symmetry

PMO-3 (Fig. 6(b)) also exhibits uniform, monomodal porosity with thicker pore walls than in the case of PMO-1, although the structure appears somewhat less ordered. The corresponding FFT data (inset to Fig. 6(c)) are also consistent with hexagonal symmetry. In contrast, the structuring of PMO-2 (Fig. 6(c), (d)) is substantially different, with two different uniform pore structures observed in different regions of the samples. Fig. 6(c) shows pores with uniform, organized hexagonal symmetry similar to those observed in Fig. 6(a) for PMO-1, with a comparable wall thickness (Table 1). On the contrary, Fig. 6(d) reveals a second population of uniform pores which appear less organized than those in Fig. 6(c), although the corresponding FFT data (inset to Fig. 6(d)) are consistent with hexagonal symmetry [14]. The wall thickness of these latter pores is substantially higher than that observed for either PMO-1 or PMO-3 (Figure 6(d) and Table 1). In addition, the TEM data presented in Fig. S5 indicates that both populations 
of mesopores identified by $\mathrm{N}_{2}$, SWAXS and TEM in the case of PMO-2 are co-located in the same particles, further highlighting the unique nature of PMO-2 and confirming that it is not a simple mixture of PMO-1 and PMO-3. As indicated above, these data are entirely consistent with the SWAXS and $\mathrm{N}_{2}$ physisorption data.

SEM micrographs of the PMOs are included in Fig. 7. The structuring observed on these length scales for PMO-1 (Fig. 7(a)) and PMO-2 (Fig. 7(b)), which both exhibit organized 2D hexagonal mesoporosity, is similar to that reported by Goto and Inagaki [36], and is consistent with a pseudo-crystalline material. In contrast PMO-3 appears substantially less ordered (Fig. 7(c)), as expected from the earlier discussion.
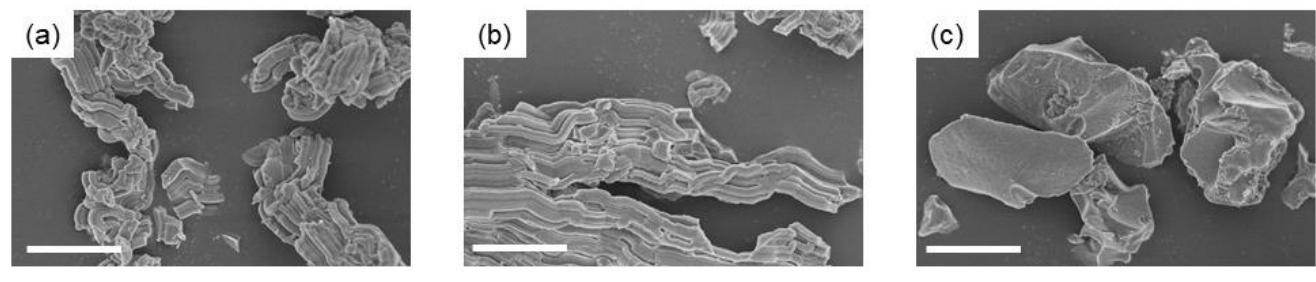

Fig. 7. SEM micrographs of PMO-1 (a); PMO-2 (b) and PMO-3 @. (Size bar: $5 \mu \mathrm{m}$ )

\subsection{Mechanism}

A notable feature of the different morphologies observed in this study is that they are obtained simply be varying the addition sequence of reactants at $0{ }^{\circ} \mathrm{C}$ during the initial 5 min of reaction at that temperature, without changing precursors and using a single surfactant. A consistent processing regime is then applied to all three systems, which involves aging of the initial structures at $35{ }^{\circ} \mathrm{C}$ for $24 \mathrm{~h}$, followed by an additional aging step at $100{ }^{\circ} \mathrm{C}$ for a further $24 \mathrm{~h}$. As previously discussed, the ${ }^{29} \mathrm{Si}-\mathrm{NMR}$ data (Fig. 1) indicates that the extent of condensation is essentially identical in all three samples, with predominantly $\mathrm{T}^{2}$ silicon species observed. Similarly, the thermogravimetric analyses 
(Fig. 2) suggests that the sample stoichiometries are similar. Hydrolysis is expected to be relatively fast under these conditions, with only minimal condensation expected (estimated $\mathrm{pH} \sim 1.2$ ) [58]. These observations suggest that the basis for the observed morphologies is largely established at $0{ }^{\circ} \mathrm{C}$ by the complex interplay between the key reaction parameters. These include hydrolysis of BTEB, $\pi-\pi$ stacking, solubilization and partitioning of the hydrolyzed and unhydrolyzed BTEB within the various domains [41] of the self-assembled (2D hexagonal) P123, H-bonding between EO (and PO) groups in the P123 chains, etc. Subsequently, increasing the reaction temperature to $35^{\circ} \mathrm{C}$ would lead to a significant increase in the rate of the relatively slow condensation step. As a consequence, the formation of the hybrid silica networks from the kinetically stable structures initially established at $0{ }^{\circ} \mathrm{C}$ will be accelerated. The network will be further consolidated by aging for an additional $24 \mathrm{~h}$ at $100{ }^{\circ} \mathrm{C}$. The key differences in the processes occurring during the initial mixing step at $0{ }^{\circ} \mathrm{C}$ are explored in more detail below and summarized schematically in Fig. 8 .

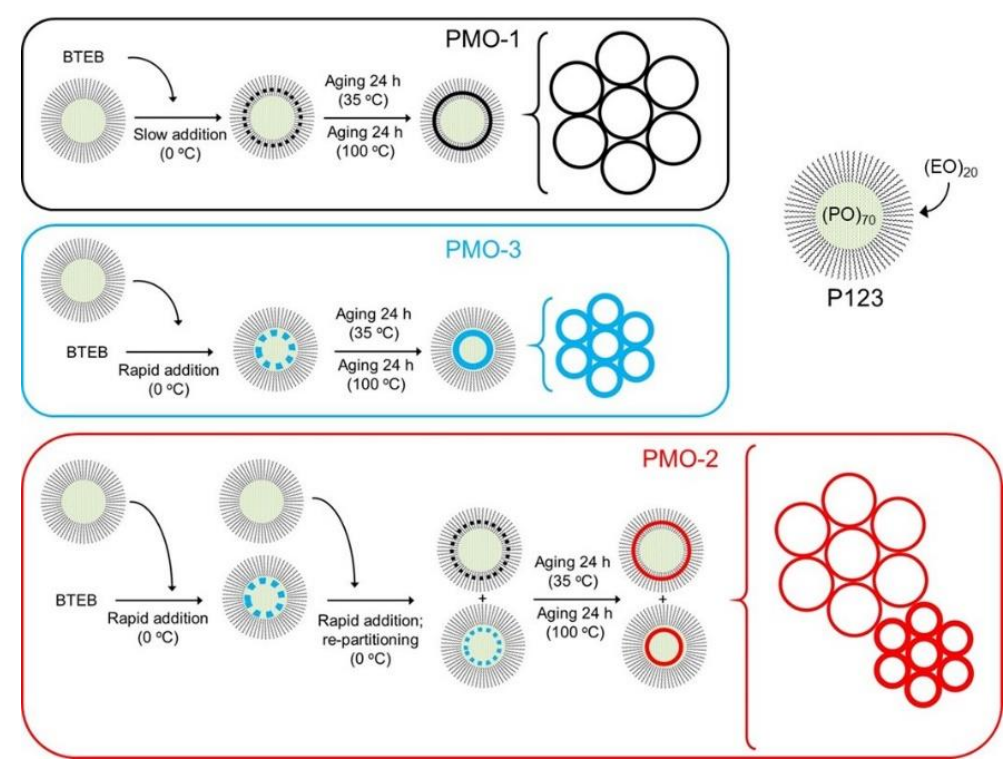

Fig. 8. Proposed mechanism for formation of uniform mesoporosity in PMO-1, PMO2 and PMO-3 


\subsubsection{PMO-1}

PMO-1 was prepared under conditions reported in earlier studies, i.e. by dropwise addition of the BTEB precursor to an acidic P123 solution [36]. The BTEB: $\mathrm{H}_{2} \mathrm{O}: \mathrm{HCl}: \mathrm{P} 123$ mole ratio is 1:800:0.95:0.07 after complete mixing of the reagents, and hence water is in large excess at all times during the reaction. A simple calculation suggests that the $\mathrm{pH}$ is around 1.2 , so hydrolysis is expected to be relatively fast and condensation relatively slow [58], as indicated above. It would be anticipated that the BTEB molecules would be rapidly hydrolyzed under the prevailing conditions, generating hydroxylated intermediates that would be less hydrophobic than the initial BTEB species. Hence, they would be expected to accumulate outside of the hydrophobic core of the self-assembled P123 structures and within the corona region, due to the competition between H-bonding of the silanol groups attached to the hydrophilic (EO) $)_{20}$ P123 groups and solubilization of the phenylene species within the hydrophobic $\left((\mathrm{PO})_{70}\right)$ core. Cerveau et al [59] reported the formation of hexasilanol species formed in biphasic systems by the controlled hydrolysis of BTEB. These are stabilized by H-bonding and $\pi-\pi$ stacking to form well-organized supramolecular species without condensation between the hexasilanol species. Such organized supramolecular species, together with smaller hydrolyzed BTEB species, would further self-assemble by $\pi-\pi$ stacking, EOsilsesquioxane H-bonding interactions and subsequent condensation to form the PMO network. This network formation would thus be expected to proceed mainly within the corona region and in close proximity to the hydrophobic (PO) 70 core, thus establishing the size of the pores in the evolving PMO network and during the subsequent aging/consolidation steps at 35 and $100{ }^{\circ} \mathrm{C}$. The SAXS pattern for PMO-1 (Fig. 5) indicates that the pores within the sample have 2D hexagonal symmetry, consistent with 
results previously reported for such materials in several studies $[19,36]$. In addition, the $\mathrm{N}_{2}$ sorption data indicates that there is essentially no microporosity in the sample, suggesting that the various aging and consolidation steps (including the three-day treatment at $100{ }^{\circ} \mathrm{C}$ ) generates well-ordered, uniform mesoporosity with few micropores.

\subsubsection{PMO-3}

The mixing sequence used to prepare PMO-3 is the reverse of that for PMO-1, insofar as the P123 solution is rapidly added to neat BTEB in the former case, albeit with only $1 / 3$ of the quantity of surfactant being used. Under these conditions, the BTEB:P123 ratio is increased three-fold compared to PMO-1 and the entire quantity of BTEB is essentially unhydrolyzed when the reactants are fully mixed. It would be expected that the more hydrophobic BTEB species would penetrate further into the hydrophobic $(\mathrm{PO})_{70}$ core of the micelles prior to hydrolysis commencing. Subsequent hydrolysis of the BTEB species should then lead to repartitioning of the BTEB moieties between the corona $(\mathrm{H}-$ bonding with EO groups) and hydrophobic core (where both solubilization of the phenyl groups and $\mathrm{H}$-bonding with the $\mathrm{PO}$ groups can occur). Under such conditions, the formation of well-organized supramolecular structures such as those discussed above [59] would be less favorable, leading to poorer long-range ordering in the evolving PMO. In addition, the higher concentration of BTEB would be more likely to promote some condensation and formation of small oligomers, which would also inhibit the formation of well-organized supramolecular structures. Due to the lower quantity of P123 used to prepare PMO-3 compared to PMO-1 (three-fold reduction), it is also evident that more silane species would be associated with each P123 micelle in the case of PMO-3. During subsequent condensation at $35^{\circ} \mathrm{C}$ to form the PMO network, the deeper initial penetration 
of BTEB precursors into the core of the self-assembled P123 aggregates would be expected to lead to a single population of smaller pores in the aged material compared to PMO-1. In addition, the larger quantity of silane precursor associated with each P123 aggregate would be expected to lead to thicker walls in the final product, as is observed.

It is evident from a comparison of the SAXS patterns of PMO-1 and PMO-3 that the uniform pore network in PMO-3 is not as ordered as that in PMO-1 (with only a single, broad peak being clearly observed, Fig. 5). This suggests that the hydrolyzed BTEB precursor is not as well organized in PMO-3 prior to condensation commencing, compared to PMO-1, as discussed above.

\subsubsection{PMO-2}

The addition sequence in the case of PMO-2 is similar to that of PMO-3. In a first step, an aliquot of the acidic P123 solution is added to neat BTEB, and hence the initial reactions occurring would be equivalent to those occurring in the case of PMO-3, with penetration of BTEB into the micelle core, H-bonding of partially hydrolyzed BTEB with both EO and PO groups, etc. However, after $5 \mathrm{~min}$, an additional aliquot of acidic P123 solution was added in the case of PMO-2, to yield a final BTEB:P123 ratio comparable to that in the case of PMO-1. Since the extent of condensation under these conditions is limited [58], it would be anticipated that some of the now-hydrolyzed BTEB species associated with the initially added P123 aggregates in the PMO-2 system would repartition into the unoccupied P123 species incorporated during addition of the second aliquot. However, unlike the conditions prevailing immediately after the addition of the first P123-solution aliquot (where the BTEB is unhydrolyzed and relatively hydrophobic), significant hydrolysis of BTEB would have occurred by the time of the 
addition of the second aliquot. Hence the conditions prevailing during re-partitioning resemble those for PMO-1, where the BTEB species interacting with unoccupied P123 micelles would be at least partly hydrolyzed, with the possible formation of small oligomers. Hence, the BTEB species would be expected to partition into the corona region of P123 micelle added in the second aliquot and to further self-assemble. During subsequent consolidation of the structure via condensation at $35^{\circ} \mathrm{C}$, a bimodal pore-size distribution would thus be established, with the pore sizes resembling those observed for PMO-1 and PMO-3. This expectation is consistent with the SAXS and $\mathrm{N}_{2}$ sorption data presented in Figs. 5 and 3, respectively, which reveals the presence of a uniform, well-ordered population of pores with 2D hexagonal symmetry (as observed for PMO-1), together with a second population of uniform pores with diameters equivalent to those found in PMO-3.

\section{Conclusion}

PMOs with uniform, organized 2D hexagonal monomodal and bimodal porosity have been prepared under acidic conditions from BTEB, using a simple approach involving a single SDA (Pluronic P123). In contrast to earlier reports, the method described herein does not require the use of co-surfactants or multiple SDAs and does not involve decomposition of the bridging organic species to generate the bimodal mesopore network. Instead, the addition sequence of the reactants and SDA is controlled to exploit the competition between key process parameters: hydrolysis, $\pi-\pi$ stacking, solubilization/partitioning of the hydrolyzed and unhydrolyzed BTEB within the various domains of the self-assembled (2D hexagonal) P123, H-bonding between EO and PO 
groups in the $\mathrm{P} 123$ chains, etc, at $0{ }^{\circ} \mathrm{C}$. Subsequent aging at 35 to $100{ }^{\circ} \mathrm{C}$ consolidates the silsesquioxane networks to generate the observed products.

The approach outlined opens up new possibilities for producing functional materials with uniform, well-organized bimodal pore networks that retain the functionality of the bridging organic species within the walls of the materials. Many potential applications for such materials can be envisaged that would be greatly enhanced, including catalysis (controlled diffusion rates of reactants and products of different dimensions); chromatography (enhanced double-size exclusion); and controlled delivery of bioactive species (tailored release profiles of mixtures of pharmaceuticals); etc.

\section{Acknowledgements}

The authors gratefully acknowledge Didier Cot (Institut Européen des Membranes, Montpellier) for SEM measurements, Frank Godiard (Plateforme Microscopie Électronique et Analytique, Université de Montpellier) for TEM measurements, as well as Philippe Gaveau and Emmanuel Fernandez (Laboratoire de Mesures Physiques, Université de Montpellier, Ecole Nationale Supérieure de Chimie de Montpellier) for solid-state NMR experiments. Funding from the French Ministère de l'Enseignement Supérieur et de la Recherche to support the PhD scholarship of ML is gratefully acknowledged.

\section{References}

[1] A.C. Pierre, G.M. Pajonk, Chemistry of aerogels and their applications, Chem. Rev., 102 (2002) 4243-4265.

[2] J.N. Armor, E.J. Carlson, P.M. Zambri, Aerogels as hydrogenation catalysts, Applied Catalysis, 19 (1985) 339-348. 
[3] A. Corma, From microporous to mesoporous molecular sieve materials and their use in catalysis, Chem. Rev., 97 (1997) 2373-2419.

[4] K.K. Unger, D. Kumar, M. Grün, G. Büchel, S. Lüdtke, T. Adam, K. Schumacher, S. Renker, Synthesis of spherical porous silicas in the micron and submicron size range: Challenges and opportunities for miniaturized high-resolution chromatographic and electrokinetic separations, J. Chromatogr. A, 892 (2000) 47-55.

[5] R. Ito, K. Morisato, K. Kanamori, K. Nakanishi, Preparation of surface-coated macroporous silica (core-shell silica monolith) for HPLC separations: Graphical Abstract, J Sol Gel Sci Technol, 90 (2019) 105-112.

[6] T. Woignier, J. Reynes, J. Phalippou, J.L. Dussossoy, N. Jacquet-Francillon, Sintered silica aerogel: A host matrix for long life nuclear wastes, J Non Cryst Solids, 225 (1998) 353-357.

[7] Y.L. He, T. Xie, Advances of thermal conductivity models of nanoscale silica aerogel insulation material, Appl Therm Eng, 81 (2015) 28-50.

[8] H. El Hamzaoui, L. Courthéoux, V.N. Nguyen, E. Berrier, A. Favre, L. Bigot, M. Bouazaoui, B. Capoen, From porous silica xerogels to bulk optical glasses: The control of densification, Mater Chem Phys, 121 (2010) 83-88.

[9] A. Zunger, Electronic-structure theory of semiconductor quantum dots, MRS Bull, 23 (1998) 35-42.

[10] D. Avnir, T. Coradin, O. Lev, J. Livage, Recent bio-applications of sol-gel materials, J. Mater. Chem., 16 (2006) 1013-1030.

[11] A.C. Pierre, The sol-gel encapsulation of enzymes, Biocatal. Biotransform., 22 (2004) 145-170. 
[12] M. Power, B. Hosticka, E. Black, C. Daitch, P. Norris, Aerogels as biosensors: Viral particle detection by bacteria immobilized on large pore aerogel, J Non Cryst Solids, 285 (2001) 303-308.

[13] J.S. Beck, J.C. Vartuli, W.J. Roth, M.E. Leonowicz, C.T. Kresge, K.D. Schmitt, C.T.W. Chu, D.H. Olson, E.W. Sheppard, S.B. McCullen, J.B. Higgins, J.L. Schlenker, A New Family of Mesoporous Molecular Sieves Prepared with Liquid Crystal Templates, J. Am. Chem. Soc., 114 (1992) 10834-10843.

[14] J.M. Kim, Y. Sakamoto, Y.K. Hwang, Y.U. Kwon, O. Terasaki, S.E. Park, G.D. Stucky, Structural design of mesoporous silica by micelle-packing control using blends of amphiphilic block copolymers, J Phys Chem B, 106 (2002) 2552-2558.

[15] M.H. Lim, C.F. Blanford, A. Stein, Synthesis and characterization of a reactive vinylfunctionalized MCM- 41: Probing the internal pore structure by a bromination reaction, J. Am. Chem. Soc., 119 (1997) 4090-4091.

[16] T. Asefa, M.J. MacLachlan, N. Coombs, G.A. Ozin, Periodic mesoporous organosilicas with organic groups inside the channel walls, Nature, 402 (1999) 867-871. [17] S. Inagaki, S. Guan, Y. Fukushima, T. Ohsuna, O. Terasaki, Novel mesoporous materials with a uniform distribution of organic groups and inorganic oxide in their frameworks, J. Am. Chem. Soc., 121 (1999) 9611-9614.

[18] B.J. Melde, B.T. Holland, C.F. Blanford, A. Stein, Mesoporous sieves with unified hybrid inorganic/organic frameworks, Chem. Mater., 11 (1999) 3302-3308.

[19] W.J. Hunks, G.A. Ozin, Challenges and advances in the chemistry of periodic mesoporous organosilicas (PMOs), J. Mater. Chem., 15 (2005) 3716-3724.

[20] W. Wang, J.E. Lofgreen, G.A. Ozin, Why PMO? Towards functionality and utility of periodic mesoporous organosilicas, Small, 6 (2010) 2634-2642. 
[21] B. Hatton, K. Landskron, W. Whitnall, D. Perovic, G.A. Ozin, Past, present, and future of periodic mesoporous organosilicas - The PMOs, Acc. Chem. Res., 38 (2005) $305-312$.

[22] F. Hoffmann, M. Cornelius, J. Morell, M. Fröba, Silica-based mesoporous organicinorganic hybrid materials, Angew. Chem. Int. Ed., 45 (2006) 3216-3251.

[23] N. Mizoshita, T. Tani, S. Inagaki, Syntheses, properties and applications of periodic mesoporous organosilicas prepared from bridged organosilane precursors, Chem. Soc. Rev., 40 (2011) 789-800.

[24] P. Van Der Voort, D. Esquivel, E. De Canck, F. Goethals, I. Van Driessche, F.J. Romero-Salguero, Periodic mesoporous organosilicas: From simple to complex bridges; A comprehensive overview of functions, morphologies and applications, Chem. Soc. Rev., 42 (2013) 3913-3955.

[25] S.S. Park, M.S. Moorthy, C.S. Ha, Periodic mesoporous organosilicas for advanced applications, NPG Asia Mater., 6 (2014) 1-21.

[26] Q. Yang, J. Liu, L. Zhang, C. Li, Functionalized periodic mesoporous organosilicas for catalysis, J. Mater. Chem., 19 (2009) 1945-1955.

[27] P. Kumar, V.V. Guliants, Periodic mesoporous organic-inorganic hybrid materials: Applications in membrane separations and adsorption, Microporous Mesoporous Mater., $132(2010) 1-14$.

[28] V. Rebbin, R. Schmidt, M. Fröba, Spherical particles of phenylene-bridged periodic mesoporous organosilica for high-performance liquid chromatography, Angew. Chem. Int. Ed., 45 (2006) 5210-5214.

[29] A. Birault, E. Molina, G. Toquer, P. Lacroix-Desmazes, N. Marcotte, C. Carcel, M. Katouli, J.R. Bartlett, C. Gérardin, M. Wong Chi Man, Large-Pore Periodic Mesoporous 
Organosilicas as Advanced Bactericide Platforms, ACS Appl. Bio Mater., 1 (2018) 17871792.

[30] Y. Chen, J. Shi, Chemistry of Mesoporous Organosilica in Nanotechnology: Molecularly Organic-Inorganic Hybridization into Frameworks, Adv Mater, 28 (2016) $3235-3272$.

[31] A. Birault, E. Molina, P. Trens, D. Cot, G. Toquer, N. Marcotte, C. Carcel, J.R. Bartlett, C. Gérardin, M. Wong Chi Man, Periodic Mesoporous Organosilicas from Polyion Complex Micelles - Effect of Organic Bridge on Nanostructure, Eur. J. Inorg. Chem., (2019) 3157-3164.

[32] J.G. Croissant, X. Cattoën, M. Wong Chi Man, J.O. Durand, N.M. Khashab, Syntheses and applications of periodic mesoporous organosilica nanoparticles, Nanoscale, 7 (2015) 20318-20334.

[33] J.G. Croissant, X. Cattoën, J.O. Durand, M. Wong Chi Man, N.M. Khashab, Organosilica hybrid nanomaterials with a high organic content: syntheses and applications of silsesquioxanes, Nanoscale, 8 (2016) 19945-19972.

[34] X. Du, X. Li, L. Xiong, X. Zhang, F. Kleitz, S.Z. Qiao, Mesoporous silica nanoparticles with organo-bridged silsesquioxane framework as innovative platforms for bioimaging and therapeutic agent delivery, Biomaterials, 91 (2016) 90-127.

[35] H.I. Lee, C. Pak, S.H. Yi, J.K. Shon, S.S. Kim, B.G. So, H. Chang, J.E. Yie, Y.U. Kwon, J.M. Kim, Systematic phase control of periodic mesoporous organosilicas using Gemini surfactants, J. Mater. Chem., 15 (2005) 4711-4717.

[36] Y. Goto, S. Inagaki, Synthesis of large-pore phenylene-bridged mesoporous organosilica using triblock copolymer surfactant, Chem. Commun., 2 (2002) 2410-2411. 
[37] T.W. Kim, F. Kleitz, B. Paul, R. Ryoo, MCM-48-like large mesoporous silicas with tailored pore structure: Facile synthesis domain in a ternary triblock copolymer-butanolwater system, J. Am. Chem. Soc., 127 (2005) 7601-7610.

[38] X.Y. Bao, X.S. Zhao, S.Z. Qiao, S.K. Bhatia, Comparative analysis of structural and morphological properties of large-pore periodic mesoporous organosilicas and pure silicas, J Phys Chem B, 108 (2004) 16441-16450.

[39] S.Z. Qiao, C.Z. Yu, Q.H. Hu, Y.G. Jin, X.F. Zhou, X.S. Zhao, G.Q. Lu, Control of ordered structure and morphology of large-pore periodic mesoporous organosilicas by inorganic salt, Microporous Mesoporous Mater., 91 (2006) 59-69.

[40] Y. Liang, E.S. Erichsen, M. Hanzlik, R. Anwander, Facile mesophase control of periodic mesoporous organosilicas under basic conditions, Chem. Mater., 20 (2008) $1451-1458$.

[41] S. Polarz, M. Antonietti, Porous materials via nanocasting procedures: Innovative materials and learning about soft-matter organization, Chem. Commun., 22 (2002) 25932604.

[42] E.B. Cho, D. Kim, M. Mandal, C.A. Gunathilake, M. Jaroniec, Benzene-silica with hexagonal and cubic ordered mesostructures synthesized in the presence of block copolymers and weak acid catalysts, J. Phys. Chem. C, 116 (2012) 16023-16029.

[43] L.Y. Xia, Y.C. Hu, M.Z. Rong, Y.J. Liang, Preparation of bifunctionalized phenylene-bridged periodic mesoporous organosilica for solid-phase microextraction, RSC Adv., 4 (2014) 168-174.

[44] E.B. Cho, M. Mandal, M. Jaroniec, Periodic mesoporous benzene-silicas prepared using boric acid as catalyst, Chem. Mater., 23 (2011) 1971-1976. 
[45] J. Sun, Z. Shan, T. Maschmeyer, J.A. Moulijn, M.O. Coppens, Synthesis of tailored bimodal mesoporous materials with independent control of the dual pore size distribution, Chem. Commun., 24 (2001) 2670-2671.

[46] A. Okabe, M. Niki, T. Fukushima, T. Aida, A simple route to bimodal mesoporous silica via tetrafluoroborate ion-mediated hydrophobic transformation of template micellar surface, J. Mater. Chem., 15 (2005) 1329-1331.

[47] M.J. Reber, D. Brühwiler, Bimodal mesoporous silica with bottleneck pores, Dalton Trans., 44 (2015) 17960-17967.

[48] L. Yang, H. Wu, J. Jia, B. Ma, J. Li, Synthesis of bimodal mesoporous silica with coexisting phases by co-hydrothermal aging route with P123 containing gel and F127 containing gel, Microporous Mesoporous Mater., 253 (2017) 151-159.

[49] J. Croissant, X. Cattoën, M. Wong Chi Man, P. Dieudonné, C. Charnay, L. Raehm, J.O. Durand, One-pot construction of multipodal hybrid periodic mesoporous organosilica nanoparticles with crystal-like architectures, Adv Mater, 27 (2015) 145-149. [50] A. Birault, E. Molina, C. Carcel, J. Bartlett, N. Marcotte, G. Toquer, P. LacroixDesmazes, C. Gérardin, M. Wong Chi Man, Synthesis of lamellar mesostructured phenylene-bridged periodic mesoporous organosilicas (PMO) templated by polyion complex (PIC) micelles, J Sol Gel Sci Technol, 89 (2019) 189-195.

[51] K.J. Shea, D.A. Loy, O. Webster, Arylsilsesquioxane Gels and Related Materials. New Hybrids of Organic and Inorganic Networks, J. Am. Chem. Soc., 114 (1992) 67006710.

[52] C. Wang, M. Zhang, W. Li, X. Huang, S. Li, S. Luan, X. Hou, Q. Wang, Investigation on the function of nonionic surfactants during compressed $\mathrm{CO} 2$-mediated periodic mesoporous organosilica formation, Soft Matter, 13 (2017) 5704-5713. 
[53] P. Trens, R. Denoyel, E. Guilloteau, Evolution of Surface Composition, Porosity, and Surface Area of Glass Fibers in a Moist Atmosphere, Langmuir, 12 (1996) 12451250.

[54] N. Rose, M. Le Bras, R. Delobel, B. Costes, Y. Henry, Thermal oxidative degradation of an epoxy resin, Polym Degradation Stab, 42 (1993) 307-316.

[55] M.T.J. Keene, R.D.M. Gougeon, R. Denoyel, R.K. Harris, J. Rouquerol, P.L. Llewellyn, Calcination of the MCM-41 mesophase: Mechanism of surfactant thermal degradation and evolution of the porosity, J. Mater. Chem., 9 (1999) 2843-2850.

[56] F. Rouquerol, J. Rouquerol, K.S.W. Sing, Adsorption by powders and porous solids: principles. methodology and applications, Academic Press, San Diego, 1999.

[57] S. Inagaki, S. Guan, T. Ohsuna, O. Terasaki, An ordered mesoporous organosilica hybrid material with a crystal-like wall structure, Nature, 416 (2002) 304-307.

[58] C.J. Brinker, Hydrolysis and condensation of silicates: Effects on structure, J Non Cryst Solids, 100 (1988) 31-50.

[59] G. Cerveau, R.J.P. Corriu, B. Dabiens, J.L. Bideau, Synthesis of stable organo(bissilanetriols): X-ray powder structure of 1,4-bis(trihydroxysilyl)benzene, Angew. Chem. Int. Ed., 39 (2000) 4533-4537. 